\title{
Nanomaterial-Based Surface-Assisted Laser Desorption/Ionization Mass Spectrometry of Peptides and Proteins
}

\author{
Cheng-Kang Chiang, Ni-Chen Chiang, Zong-Hong Lin, Guo-Yu Lan, \\ Yang-Wei Lin, and Huan-Tsung Chang \\ Department of Chemistry, National Taiwan University, Taipei, Taiwan
}

We have investigated six nanomaterials for their applicability as surfaces for the analyses of peptides and proteins using surface-assisted laser desorption/ionization mass spectrometry (SALDI-MS). Gold nanoparticles (NPs) were useful nanomaterials for small analytes (e.g., glutathione); $\mathrm{Pt}$ nanosponges and $\mathrm{Fe}_{3} \mathrm{O}_{4} \mathrm{NPs}$ were efficient nanomaterials for proteins, with an upper detectable mass limit of ca. $25 \mathrm{kDa}$. Nanomaterials have several advantages over organic matrices, including lower limits of detection for small analytes and lower batch-to-batch variations (fewer problems associated with "sweet spots"), when used in laser desorption/ionization mass spectrometry. (J Am Soc Mass Spectrom 2010, 21, 1204-1207) (C) 2010 American Society for Mass Spectrometry

S urface-assisted laser desorption/ionization mass spectrometry (SALDI-MS) was developed recently using nanomaterials rather than organic compounds as matrices, for the determination of analytes of interest. For example, laser desorption/ionization (LDI) of intact proteins and protein aggregates in the presence of glycerol has been demonstrated using cobalt particles (ca. $30 \mathrm{~nm}$ ) [1]. Similar to the role played by organic matrices, the particles absorb energy from the laser irradiation and transfer it efficiently to the analytes, thereby inducing desorption and ionization. Mixtures of graphite particles $(2-150 \mu \mathrm{m})$ and glycerol have been employed in the analysis of proteins and peptides $[2,3]$. Several other nanomaterials, including carbon nanotubes, nanodiamonds, and various nanoparticles (NPs, namely $\mathrm{SiO}_{2}, \mathrm{ZnS}, \mathrm{TiO}_{2}, \mathrm{Fe}_{3} \mathrm{O}_{4}, \mathrm{Fe}_{3} \mathrm{O}_{4} / \mathrm{TiO}_{2}$, and $\mathrm{Au}$ ) are also useful - without the addition of glycerol-for SALDI-MS [4-12]. Because of their unique chemical and physical properties, NPs can also act as selective probes and/or efficient ionization nanomaterials. For example, $\mathrm{Au}$ and $\mathrm{TiO}_{2}$ NPs are suitable for the concentration and ionization of aminothiols and catechins, respectively, in SALDI-MS $[8,11]$. One other advantage of using NPs is that fewer "sweet spots" are formed, thereby maximizing reproducibility. Although NPs have been used successfully for the determination of a range of analytes (from small analytes to proteins), a review of the literature reveals that the various NPs provide quite different results in terms of sensitivity, reproducibility, and mass range. Thus, our aim in this study was to

Address reprint requests to Dr. H.-T. Chang, Department of Chemistry, National Taiwan University, 1, Section 4, Roosevelt Road, Taipei 106, Taiwan. E-mail: changht@ntu.edu.tw evaluate the performance of several types of NPs for the analysis of peptides and proteins.

\section{Experimental}

Six nanomaterials-Au NPs, $\mathrm{TiO}_{2} \mathrm{NPs}$, Se NPs, CdTe quantum dots (QDs), $\mathrm{Fe}_{3} \mathrm{O}_{4} \mathrm{NPs}$, and Pt nanosponges (NSPs) - were tested for the SALDI-MS-based analyses of peptides and proteins; they were prepared in aqueous solutions and characterized according to procedures described in the literature $[8,11,13-16]$. A twolayer preparation method was applied to deposit the nanomaterials and samples onto the metal plates used in SALDI-MS. First, one of the nanomaterial solutions (1 $\mu \mathrm{L}$ ) was deposited into one of the wells of the MS plate and dried under ambient conditions for at least $1 \mathrm{~h}$. Next, one of the sample solutions $(1 \mu \mathrm{L})$ was added into the well. Each sample solution contained one of the following analytes: glutathione ( $\mathrm{MW}=307.32 \mathrm{Da})$, angiotensin I (1296.48 Da), insulin (5734.52 Da), cytochrome $c$ (ca. $12 \mathrm{kDa}$ ), trypsinogen (ca. $24 \mathrm{kDa})$, and chymotrypsin (ca. $25 \mathrm{kDa}$ ). The aqueous sample solutions were premixed with ammonium citrate buffer (0.5-50 mM; pH 4.0); the ammonium ions acted as proton sources for the SALDI process [8-10]. After drying under ambient conditions, the samples were subjected to SALDI-MS analysis.

Mass spectrometry experiments were performed in the positive or negative ion mode using a Microflex MALDI-TOF mass spectrometer (Bruker Daltonics, Bremen, Germany). A pulsed nitrogen laser (337 nm; 3-ns pulses at $10.0 \mathrm{~Hz}$; fluence $40-66.25 \mu \mathrm{J}$ ) was used in the MS system, which was operated in the reflectron (or linear) mode with an ion source voltage of 19.00 (20.00) 
$\mathrm{kV}$, a second ion source voltage of 16.25 (18.40) $\mathrm{kV}$, a lens voltage of $9.70(7.00) \mathrm{kV}$, a reflector voltage of 20.0 (20.0) kV, and an extraction delay time of 200 (450) ns. MALDI mass spectra resulting from 300 laser pulses were collected and averaged for each acquisition.

\section{Results and Discussion}

Table S1, which can be found in the electronic version of this article summarizes the pseudomolecular ions observed from the analytes when using these six nanomaterials in SALDI-MS. Although the Au NPs were selective and efficient nanomaterials for glutathione, they were not useful for the analysis of analytes having values of $m / z$ greater than 1300 . When using the Se NPs, $\mathrm{TiO}_{2}$ NPs, and CdTe QDs for SALDI-MS analyses, the mass range reached as high as the mass of cytochrome $c$. The SALDI-MS approach allowed the detection of chymotrypsin by using the Pt NSPs and $\mathrm{Fe}_{3} \mathrm{O}_{4}$ NPs. Interestingly, we detected the $[\mathrm{M}-\mathrm{H}]^{-}$ion of glutathione when using the $\mathrm{TiO}_{2}$ NPs for SALDI-MS measurement, but the $[\mathrm{M}+\mathrm{Na}]^{+}$ion when using the other five nanomaterials (Table S1). For angiotensin I, we detected the $[\mathrm{M}+\mathrm{H}]^{+}$and $[\mathrm{M}+\mathrm{Na}]^{+}$ions in all six cases; in addition, we also detected the $[\mathrm{M}+\mathrm{K}]^{+}$ion when using the $\mathrm{Fe}_{3} \mathrm{O}_{4}$ NPs. When using $\mathrm{Fe}_{3} \mathrm{O}_{4}$ NPs and CdTe QDs in the analysis of insulin, we detected adducts of $\mathrm{Fe}$ and $\mathrm{Cd}$, respectively. Presumably, the formation of metal-analyte adducts was due to strong interactions between the $\mathrm{Fe}^{3+} / \mathrm{Cd}^{2+}$ ions and the proteins through metal-ligand (carboxylate and amino) coordination [9]. We detected a greater number of adducts for the larger protein cytochrome $c$ when using the $\mathrm{Fe}_{3} \mathrm{O}_{4}$ NPs and CdTe QDs, mainly because there were more $\mathrm{Fe}$ ions desorbed and ionized from the NPs than those from the mixtures of the metal ions (low concentrations) and sinapinic acid (SA). For comparison, we also recorded the mass spectra of cytochrome $c$ using SA as the matrix in the absence and presence of $\mathrm{Fe}^{3+}$ or $\mathrm{Cd}^{2+}$ ions. Figure $\mathrm{S} 1 \mathrm{a}$, which can be found in the electronic version of this article, presents the mass spectrum of cytochrome $c$ obtained using SA (10 mg/ $\mathrm{mL})$ containing $\mathrm{Fe}^{3+}$ ions $(1 \mathrm{mM})$ as the matrix. Although we observed the formation of Fe-analyte adducts, the most abundant peak corresponds to the [M + $\mathrm{H}]^{+}$ion; in contrast, Figure $1\left(\mathrm{Fe}_{3} \mathrm{O}_{4} \mathrm{NPs}\right)$ reveals that the most abundant peaks were those of $\mathrm{Fe}$-analyte adducts. In the absence of $\mathrm{Fe}^{3+}$ (Figure S1b), we detected no Fe-analyte adducts. Figure S1a and $b$ both reveal the formation of SA-analyte adducts. We also observed $\mathrm{Cd}$-cytochrome $c$ adducts when analyzing cytochrome $c$ using either CdTe QDs as the nanomaterials or $\mathrm{SA}(10 \mathrm{mg} / \mathrm{mL})$ and added $\mathrm{Cd}^{2+}$ ions $(1 \mathrm{mM})$ as the matrices, and the $[\mathrm{M}+\mathrm{H}]^{+}$ion when using SA as the matrix (data not shown). The limits of detection (LODs; signal-to-noise ratio $=3$ ) for cytochrome $c$ was ca. $5.6 \mathrm{fmol}$ when using the $\mathrm{Fe}_{3} \mathrm{O}_{4}$ NPs in SALDI-MS, much lower than that $\left(2.5 \times 10^{4} \mathrm{fmol}\right)$ obtained when using the CdTe QDs. When using the $\mathrm{Fe}_{3} \mathrm{O}_{4}$ NPs and CdTe QDs in SALDI-MS measurements, the intensities of the signals for the metal adducts varied by 16 and $26 \%$, respectively, over 50 sample spots; in contrast, the

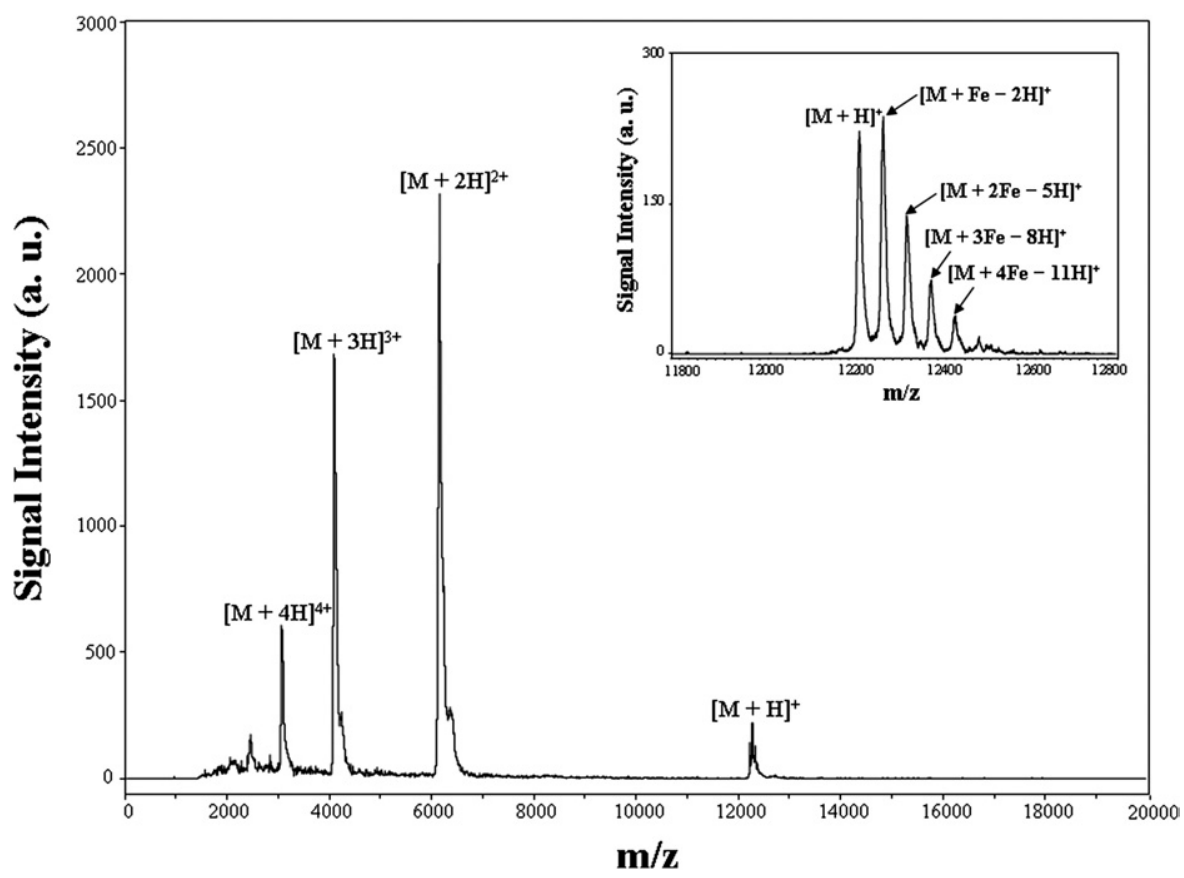

Figure 1. Surface-assisted laser desorption ionization (SALDI) mass spectrum of cytochrome $c$ (50 pmol) recorded at $51.25 \mu \mathrm{J}$ using $\mathrm{Fe}_{3} \mathrm{O}_{4}$ nanoparticles (NPs) $(800 \mathrm{nM}, 1 \mu \mathrm{L})$, prepared in $50 \mathrm{mM}$ ammonium citrate $(\mathrm{pH}$ 4.0). Inset: SALDI mass spectrum of cytochrome $c$ in the range $\mathrm{m} / \mathrm{z}$ $11,800-12,800$. 
variations were greater than $50 \%$ when using SA as the matrix, either in the absence or presence of $\mathrm{Fe}^{3+}$ or $\mathrm{Cd}^{2+}$ ions.

Figure S2 presents the SALDI mass spectra of cytochrome $c$, trypsinogen, and chymotrypsin that we obtained using the Pt NSPs. Unlike the situation for the Au nanomaterials, which produced many Au clusters, we did not detect any Pt clusters when using the Pt NSPs as the nanomaterials, primarily because of the relatively low thermal conductivity of $\mathrm{Pt}\left(71.6 \mathrm{~W} \mathrm{~m}^{-1}\right.$ $\mathrm{K}^{-1}$ at $300 \mathrm{~K}$; cf. $318 \mathrm{~m}^{-1} \mathrm{~K}^{-1}$ for $\mathrm{Au}$ ) [17]. For small analytes (e.g., glutathione), the Au NPs provided much better sensitivity than did the Pt NSPs, mainly due to more-efficient desorption and ionization. The mass limit reached only 5735.49 Da (insulin) when using the $\mathrm{Au}$ NPs, primarily because of strong interactions (through Au-S bonds) between the Au NPs and the analytes. Compared with the $\mathrm{Fe}_{3} \mathrm{O}_{4}, \mathrm{TiO}_{2}$, and $\mathrm{CdTe}$ nanomaterials, the Pt NSPs required less laser energy (ca. $40-43.75 \mu \mathrm{J}$ ) to induce the desorption and ionization of either cytochrome $c$ or chymotrypsin, mainly because of the relatively higher thermal conductivity of
Pt. Larger molecules have more adsorption sites for their binding to the surfaces of inorganic materials, making it much more difficult to detach them. Therefore, macromolecules require a higher laser power than do small molecules for detection using SALDI-MS. Because we employed lower laser energies when using the Pt NSPs, fewer fragment ions were formed. Furthermore, the Pt NSPs featured surface projections that acted as tiny antennas, producing significant field enhancements in their vicinity, leading to greater desorption and ionization efficiency. Indeed, relative to the $\mathrm{Fe}_{3} \mathrm{O}_{4} \mathrm{NPs}$, the Pt NSPs provided very clean mass patterns for the analysis of proteins. We detected multiply charged ions for cytochrome $c$, trypsinogen, and chymotrypsin when using the $\mathrm{Fe}_{3} \mathrm{O}_{4}$ NPs for SALDI-MS analyses. In our experiments, $\mathrm{NH}_{4}{ }^{+}$ions acted as the main proton donors during the desorption and ionization processes. Notably, we had prepared the $\mathrm{Fe}_{3} \mathrm{O}_{4}$ NPs from an ammonia solution under basic conditions. We observed similar results when analyzing cytochrome $c$ using the $\mathrm{TiO}_{2}$ NPs as the added nanomate-

Table 1. Experimental parameters, linear ranges (LR), limits of detection (LOD), coefficients of variation (CV), and mass spectral ranges for the SALDI-MS analyses of the various analytes using the six nanomaterials ${ }^{\mathrm{a}}$

\begin{tabular}{|c|c|c|c|c|c|c|c|}
\hline $\begin{array}{l}\text { Nanomaterial/ } \\
\text { diameter }(\mathrm{nm})^{\mathrm{b}}\end{array}$ & Analyte & $\begin{array}{c}\text { Concentration } \\
\text { of NPs }\end{array}$ & $\begin{array}{c}\text { Laser power } \\
(\mu \mathrm{J})\end{array}$ & LR (pmol) & LOD (fmol) & $\mathrm{CV}$ & $\begin{array}{l}\text { MS range } \\
(\mathrm{Da})^{\mathrm{d}}\end{array}$ \\
\hline \multirow[t]{5}{*}{$\mathrm{Au} \mathrm{NPs} / 14( \pm 2)$} & Glutathione $^{c}$ & $15 \mathrm{nM}$ & 43.75 & $2.5-100$ & $1.4 \times 10^{2}$ & $18 \%$ & $300-1,300$ \\
\hline & Angiotensin I & $15 \mathrm{nM}$ & 43.75 & $2-50$ & $8.1 \times 10^{2}$ & $29 \%$ & \\
\hline & Insulin & $1.5 \mathrm{nM}$ & 47.5 & - & $7.7 \times 10^{3}$ & $25 \%$ & \\
\hline & Cytochrome $c$ & - & - & - & ND & - & \\
\hline & Chymotrypsin & - & - & - & ND & - & \\
\hline \multirow[t]{5}{*}{$\mathrm{TiO}_{2} \mathrm{NPs} / 5( \pm 1)$} & Glutathione & $24 \mathrm{nM}$ & 55 & $20-100$ & $2.2 \times 10^{3}$ & $9 \%$ & $1,200-12,000$ \\
\hline & Angiotensin I & $24 \mathrm{nM}$ & 55 & $0.4-20$ & $8.3 \times 10^{1}$ & $23 \%$ & \\
\hline & Insulin & $24 \mathrm{nM}$ & 55 & - & $4.7 \times 10^{1}$ & $25 \%$ & \\
\hline & Cytochrome $c$ & $24 \mu \mathrm{M}$ & 62.5 & - & $1.5 \times 10^{4}$ & $20 \%$ & \\
\hline & Chymotrypsin & - & - & - & ND & - & \\
\hline \multirow[t]{5}{*}{ Se NPs/100 $( \pm 10)$} & Glutathione & $50 \mathrm{pM}$ & 43.75 & - & $3.3 \times 10^{4}$ & $19 \%$ & $1,200-12,000$ \\
\hline & Angiotensin I & $1 \mathrm{nM}$ & 47.5 & $0.4-30$ & $1.6 \times 10^{2}$ & $29 \%$ & \\
\hline & Insulin & $1 \mathrm{nM}$ & 43.75 & - & $1.8 \times 10^{1}$ & $25 \%$ & \\
\hline & Cytochrome $c$ & $1 \mathrm{nM}$ & 55 & - & $2.3 \times 10^{3}$ & $27 \%$ & \\
\hline & Chymotrypsin & - & - & - & ND & - & \\
\hline \multirow[t]{5}{*}{ CdTe QDs/3 $( \pm 0.5)$} & Glutathione & $500 \mathrm{nM}$ & 43.75 & $4-100$ & $1.9 \times 10^{2}$ & $25 \%$ & $300-12,000$ \\
\hline & Angiotensin $\mathrm{I}^{\mathrm{C}}$ & $500 \mathrm{nM}$ & 47.5 & $0.4-50$ & $1.1 \times 10^{1}$ & $16 \%$ & \\
\hline & Insulin & $500 \mathrm{nM}$ & 58.75 & - & $1.4 \times 10^{1}$ & $23 \%$ & \\
\hline & Cytochrome $c$ & $25 \mu \mathrm{M}$ & 66.25 & - & $2.5 \times 10^{4}$ & $26 \%$ & \\
\hline & Chymotrypsin & - & - & - & ND & - & \\
\hline \multirow[t]{5}{*}{$\mathrm{Fe}_{3} \mathrm{O}_{4} \mathrm{NPs} / 13( \pm 3)$} & Glutathione & $8 \mathrm{nM}$ & 47.5 & $30-200$ & $8.3 \times 10^{3}$ & $14 \%$ & $1,200-25,000$ \\
\hline & Angiotensin I & 80 nM & 47.5 & $0.1-3$ & $9.8 \times 10^{1}$ & $7 \%$ & \\
\hline & Insulinc & $800 \mathrm{nM}$ & 51.25 & - & $1.2 \times 10^{1}$ & $15 \%$ & \\
\hline & Cytochrome $c^{c}$ & $800 \mathrm{nM}$ & 51.25 & - & 5.6 & $16 \%$ & \\
\hline & Chymotrypsin & $4 \mu \mathrm{M}$ & 55 & - & $4.4 \times 10^{4}$ & $20 \%$ & \\
\hline \multirow[t]{5}{*}{ Pt NSPs/37 $( \pm 6)$} & Glutathione & $10 \mathrm{pM}$ & 43.75 & - & $2.3 \times 10^{4}$ & $17 \%$ & $1,200-25,000$ \\
\hline & Angiotensin I & $50 \mathrm{pM}$ & 43.75 & $0.1-70$ & $4.3 \times 10^{1}$ & $16 \%$ & \\
\hline & Insulin & $50 \mathrm{pM}$ & 47.5 & - & $3.6 \times 10^{1}$ & $17 \%$ & \\
\hline & Cytochrome $c$ & $4 \mathrm{nM}$ & 40 & - & $1.5 \times 10^{4}$ & $35 \%$ & \\
\hline & Chymotrypsin ${ }^{c}$ & $8 \mathrm{nM}$ & 43.75 & - & $1.1 \times 10^{4}$ & $32 \%$ & \\
\hline
\end{tabular}

$\mathrm{ND}=$ Not detected in the mass spectrum.

${ }^{a}$ All experiments were performed in linear positive (for $\mathrm{m} / \mathrm{z}>6000$ ) or reflectron positive (for $\mathrm{m} / \mathrm{z}<6000$ ) modes, except for the reflectron negative mode used for the detection of glutathione using $\mathrm{TiO}_{2}$.

bizes of the nanomaterials were calculated from five different batches by counting 100 particles in each grid.

${ }^{\mathrm{c}}$ Analyte exhibiting the best sensitivity among the six nanomaterials.

dOptimal MS range of analytes for a given nanomaterial. 
rial; notably, the $\mathrm{TiO}_{2}$ NPs had been prepared under acidic conditions.

Table 1 summarizes the SALDI-MS analyses of the five analytes using the six nanomaterials through SALDI-MS measurement. For small analytes (e.g., glutathione), the $\mathrm{Au}$ NPs provided the lowest LOD (140 fmol). Upon increasing the mass of the analytes, the LODs increased as a result of their stronger interactions with $\mathrm{Au}$ NP surfaces and greater ionization energies. Because we required high laser powers for the larger molecules (MW: $>12 \mathrm{kDa}$ ), Au clusters caused suppression of the sample ion peaks and difficulty in peak assignment. CdTe QDs provided good sensitivity for analytes in the mass range from $330.07 \mathrm{Da}$ to $12 \mathrm{kDa}$. Among the six nanomaterials, the $\mathrm{Fe}_{3} \mathrm{O}_{4} \mathrm{NPs}$ and $\mathrm{Pt}$ NSPs provided the greatest sensitivity for larger proteins $(12-25 \mathrm{kDa})$. Relative to the Pt NSPs, the $\mathrm{Fe}_{3} \mathrm{O}_{4}$ NPs provided better sensitivity (LOD $=5.6 \mathrm{fmol}$ versus 15 pmol) for cytochrome $c$, but poorer sensitivity for chymotrypsin (LOD $=44 \mathrm{pmol}$ versus $11 \mathrm{pmol}$ ). Table 1 also provides a quick reference guide for the NPs most suitable for certain molecular-weight ranges of analytes. We note that the mass limits obtained using $\mathrm{Fe}_{3} \mathrm{O}_{4} \mathrm{NPs}$ and $\mathrm{Pt}$ NSPs are the highest ever reported for SALDIMS; indeed, they are higher than those reported when using silane-immobilized $\mathrm{Fe}_{3} \mathrm{O}_{4} \mathrm{NPs}\left(16 \mathrm{kDa}\right.$ ) or $\mathrm{Fe}_{3} \mathrm{O}_{4}$ / $\mathrm{TiO}_{2}$ core/shell NPs $(24 \mathrm{kDa})[9,10]$. When using the Pt NSPs for SALDI-MS analyses, the batch-to-batch variations for the smaller $(<12 \mathrm{kDa})$ and larger $(12-25 \mathrm{kDa})$ proteins were $16 \%$ and $35 \%$, respectively.

\section{Conclusions}

We have tested six nanomaterials for their suitability in SALDI-MS for the detection of small peptides and proteins (307.3 Da-25 kDa). Au NPs provided the best sensitivity for small analytes; Pt NSPs and $\mathrm{Fe}_{3} \mathrm{O}_{4}$ NPs provided the highest mass limit $(25 \mathrm{kDa})$ for proteins. To the best of our knowledge, this paper is the first to describe the use of Pt NSPs for SALDI-MS analyses. For efficient desorption and ionization, the nanomaterial must absorb laser energy efficiently and transfer it to the analytes efficiently, but its interactions with the analytes must not be too strong. For high sensitivity, the nanomaterial must be stable under laser irradiation and only minimally form clusters (e.g., Au clusters). To provide selectivity for certain analytes, aptamers and antibodies can be used to prepare functionalized Pt NSPs through strong Pt-S or Pt-N bonding [18]. The bond energies for Pt-S and Pt-N are 174 and $137 \mathrm{~kJ} / \mathrm{mol}$, respectively, which are higher that that of Au-S bonding $(134 \mathrm{~kJ} / \mathrm{mol})$. For example, we can prepare 11-mercapto3,6,9-trioxaundecyl-r-D-mannopyranoside and aptamer functionalized Pt NSPs for the detections of concanavalin and platelet-derived growth factors, respectively, through SALDI-MS [19, 20].

\section{Acknowledgments}

The authors acknowledge support for this study by the National Science Council of Taiwan under contracts NSC 98-2113-M-002011-MY3, 98-2627-M-002-013, and 98-2627-M-002-014.

\section{Appendix A Supplementary Material}

Supplementary data associated with this article can be found, in the online version, at doi:10.1016/j.jasms.2010. 02.028 .

\section{References}

1. Tanaka, K.; Waki, H.; Ido, Y.; Akita, S.; Yoshida, Y.; Yoshida, T.; Matsuo, T. Protein and Polymer Analyses up to $m / z 100000$ by Laser Ionization Time-of-Flight Mass Spectrometry. Rapid Commun. Mass Spectrom. 1988, 2, 151-153.

2. Sunner, J.; Dratz, E.; Chen, Y.-C. Graphite Surface Assisted Laser Desorption/Ionization Time-of-Flight Mass-Spectrometry of Peptides and Proteins from Liquid Solutions. Anal. Chem. 1995, 67, 4335-4342.

3. Dale, M.; Knochenmuss, R.; Zenobi, R. Graphite/Liquid Mixed Matrices for Laser Desorption/Ionization Mass Spectrometry. Anal. Chem. 1996, $68,3321-3329$.

4. Ugarov, M. V.; Egan, T.; Khabashesku, D. V.; Schultz, J. A.; Peng, H.; Khabashesku, V. N.; Furutani, H.; Prather, K. S.; Wang, H.-W. J.; Jackson, S. N.; Woods, A. S. MALDI Matrices for Biomolecular Analysis Based on Functionalized Carbon Nanomaterials. Anal. Chem. 2004, 76, 6734-6742.

5. Najam-ul-Haq, M.; Rainer, M.; Huck, C. W.; Hausberger, P.; Kraushaar, H.; Bonn, G. K. Nanostructured Diamond-Like Carbon on Digital Versatile Disc as a Matrix-Free Target for Laser Desorption/Ionization Mass Spectrometry. Anal. Chem. 2008, 80, 7467-7472.

6. Wen, X.; Dagan, S.; Wysocki, V. H. Small-Molecule Analysis with Silicon-Nanoparticle-Assisted Laser Desorption/Ionization Mass Spectrometry. Anal. Chem. 2007, 79, 434-444.

7. Kailasa, S. K.; Kiran, K.; Wu, H.-F. Comparison of ZnS Semiconductor Nanoparticles Capped with Various Functional Groups as the Matrix and Affinity Probes for Rapid Analysis of Cyclodextrins and Proteins in Surface-Assisted Laser Desorption/Ionization Time-of-Flight Mass Spectrometry. Anal. Chem. 2008, 80, 9681-9688.

8. Huang, Y.-F.; Chang, H.-T. Nile Red-Adsorbed Gold Nanoparticle Matrixes for Determining Aminothiols Through Surface-Assisted Laser Desorption/Ionization Mass Spectrometry. Anal. Chem. 2006, 78, 1485-1493.

9. Chen, W.-Y.; Chen, Y.-C. Affinity-Based Mass Spectrometry Using Magnetic Iron Oxide Particles as the Matrix and Concentrating Probes for SALDI MS Analysis of Peptides and Proteins. Anal. Bioanal. Chem. 2006, 386, 699-704.

10. Chen, C.-T.; Chen, Y.-C. $\mathrm{Fe}_{3} \mathrm{O}_{4} / \mathrm{TiO}_{2}$ Core/Shell Nanoparticles as Affinity Probes for the Analysis of Phosphopeptides Using $\mathrm{TiO}_{2}$ Surface-Assisted Laser Desorption/Ionization Mass Spectrometry. Anal. Chem. 2005, 77, 5912-5919.

11. Lee, K.-H.; Chiang, C.-K.; Lin, Z.-H.; Chang, H.-T. Determining Enediol Compounds in Tea Using Surface-Assisted Laser Desorption/Ionization Mass Spectrometry with Titanium Dioxide Nanoparticle Matrices. Rapid Commun. Mass Spectrom. 2007, 21, 2023-2030.

12. McLean, J. A.; Stumpo, K. A.; Russell, D. H. Size-Selected (2-10 nm) Gold Nanoparticles for Matrix Assisted Laser Desorption Ionization of Peptides. J. Am. Chem. Soc. 2005, 127, 5304-5305.

13. Lin, Z.-H.; Wang, C. R. C. Evidence on the Size-Dependent Absorption Spectral Evolution of Selenium Nanoparticles. Mater. Chem. Phys. 2005, 92, 591-594.

14. Gao, M.; Kirstein, S.; Möhwald, H.; Rogach, A. L.; Kornowski, A.; Eychmüller, A.; Weller, H. Strongly Photoluminescent CdTe Nanocrystals by Proper Surface Modification. J. Phys. Chem. B 1998, 102, 8360-8363.

15. Smith, J. E.; Medley, C. D.; Tang, Z.; Shangguan, D.; Lofton, C.; Tan, W. Aptamer-Conjugated Nanoparticles for Selective Collection and Detection of Cancer Cells. Anal. Chem. 2006, 78, 2918-2924.

16. Lin, Z.-H.; Lin, M.-H.; Chang, H.-T. Facile Synthesis of Catalytically Active Platinum Nanosponges, Nanonetworks, and Nanodendrites. Chem. Eur. J. 2009, 15, 4656-4662.

17. Kawasaki, H.; Yonezawa, T.; Watanabe, T.; Arakawa, R. Platinum Nanoflowers for Surface-Assisted Laser Desorption/Ionization Mass Spectrometry of Biomolecules. J. Phys. Chem. C 2007, 111, 16278-16283.

18. Kiguchi, M.; Miura, S.; Takahashi, T.; Hara, K.; Sawamura, M.; Murakoshi, K. Conductance of Single 1,4-Benzenediamine Molecule Bridging between Au and Pt Electrodes. J. Phys. Chem. C 2008, 112, 13349-13352.

19. Huang, C.-C.; Chen, C.-T.; Shiang, Y.-C.; Lin, Z.-H.; Chang, H.-T. Synthesis of Fluorescent Carbohydrate-Protected $\mathrm{Au}$ Nanodots for Detection of Concanavalin A and Escherichia coli. Anal. Chem. 2009, 81, 875-882.

20. Huang, C.-C.; Chiang, C.-K.; Lin, Z.-H.; Lee, K.-H.; Chang, H.-T. Bioconjugated Gold Nanodots and Nanoparticles for Protein Assays Based on Photoluminescence Quenching. Anal. Chem. 2008, 80, 1497-1504. 